\title{
KNUCKLE PADS CAUSING EXTENSOR TENDON TETHERING
}

\author{
A. ADDISON \\ From West Cumberland Hospital, Whitehaven
}

\begin{abstract}
A case of Dupuytren's contracture is described, in which, both clinically and histologically, knuckle pad lesions involved the extensor tendons. Surgical excision of the Dupuytren's tissue from the dorsal aspect of the proximal interphalangeal joints, freeing of the lateral extensor slips and posterior capsulotomy resulted in marked functional improvement.
\end{abstract}

Garrod first described knuckle pads in 1893. A survey by Mikkelsen (1977) in Norway found the incidence of knuckle pads in the general population over the age of 16 years to be 9 per cent in men and 8.6 per cent in women. However, in those with Dupuytren's contracture, the incidence of pads was four times as high. Wilson (1972) reported occupational knuckle pads in sheep shearers.

Generally, knuckle pads are considered benign, occasionally associated with pain when they first appear, sometimes cosmetically embarrassing and sometimes spontaneously disappearing. of the palmar nodule is found either clinically or at operation.

A case is presented in which a significant functional disability resulted from the knuckle pads.

\section{CASE REPORT}

A 33-year-old man was referred to the Hand Unit, at the Royal National Orthopaedic Hospital, London, in 1981 with Dupuytren's contracture affecting the right hand. The hand had first begun to trouble him two years
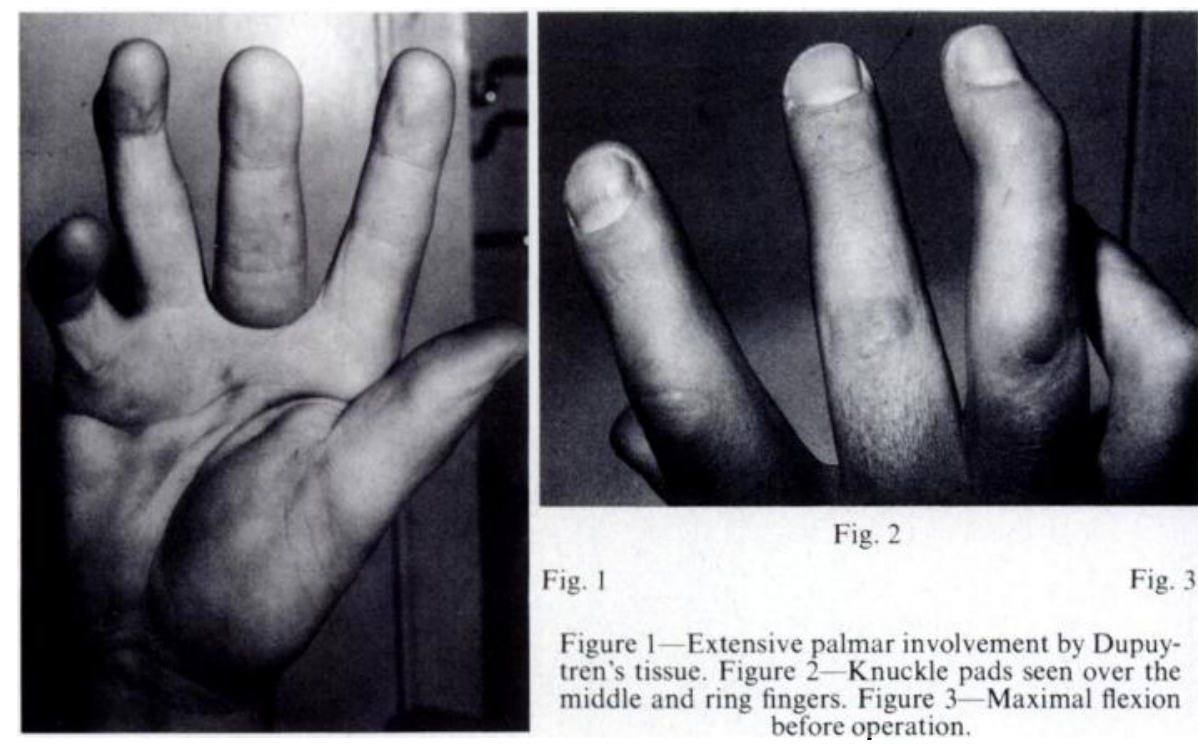

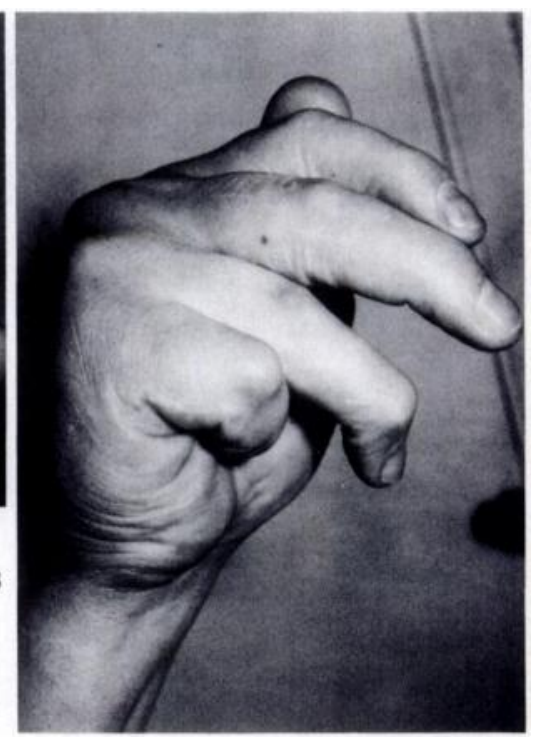

Hueston (1963) observed that it is usually possible to determine a plane of cleavage between the knuckle pads and the fibres of the tendon itself, and that there is no extension through the tendon into the joint or capsule. Moreover, no evidence of centripetal contracture typical

A. Addison, MA, FRCS, Consultant Orthopaedic Surgeon West Cumberland Hospital. Hensingham. Whitehaven, Cumbria, CA28 8JG, England.

(C) 1984 British Editorial Society of Bone and Joint Surgery $0301-620 \mathrm{X} / 84 / 1013 \$ 2.00$ previously and a band of Dupuytren's tissue had been removed from the little finger and palm 18 months before he presented to our unit.

Medical history. His left hand had been affected by the same condition and had been operated upon some years before. He had noted nodules in his feet when in his early twenties, but these had always been asymptomatic. Also, whilst in his early twenties, he had been a heavy drinker, but recently his alcohol intake had been drastically reduced. His father had had excision of Dupuytren's tissue from both hands at the age of 50 . 


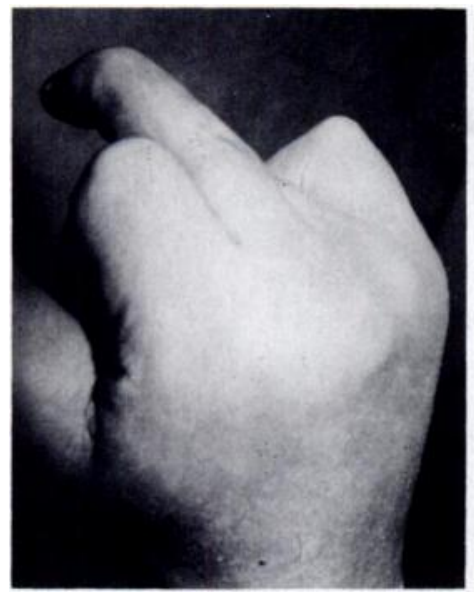

Fig. 4

Range of finger flexion after palmar fasciectomy. The middle finger shows lack of flexion, and the ring finger also lacked flexion at the proximal interphalangeal joint.

Examination. He was noted to have extensive palmar involvement by Dupuytren's tissue (Fig. 1). Knuckle pads were present over the proximal interphalangeal joints of the middle and ring fingers and the skin was tethered to the deep structures (Fig. 2). The range of flexion and extension of the fingers was grossly limited and only the little finger could be flexed fully (Fig. 3).

Operations. In November 1981 he underwent partial fasciectomy and excision of Dupuytren's tissue from the palm of the right hand. The wounds healed well and the range of finger flexion significantly increased (Fig. 4). However, the middle and ring fingers could not be flexed at the proximal interphalangeal joint and the overlying knuckle pads appeared to be tethering the extensor mechanism.

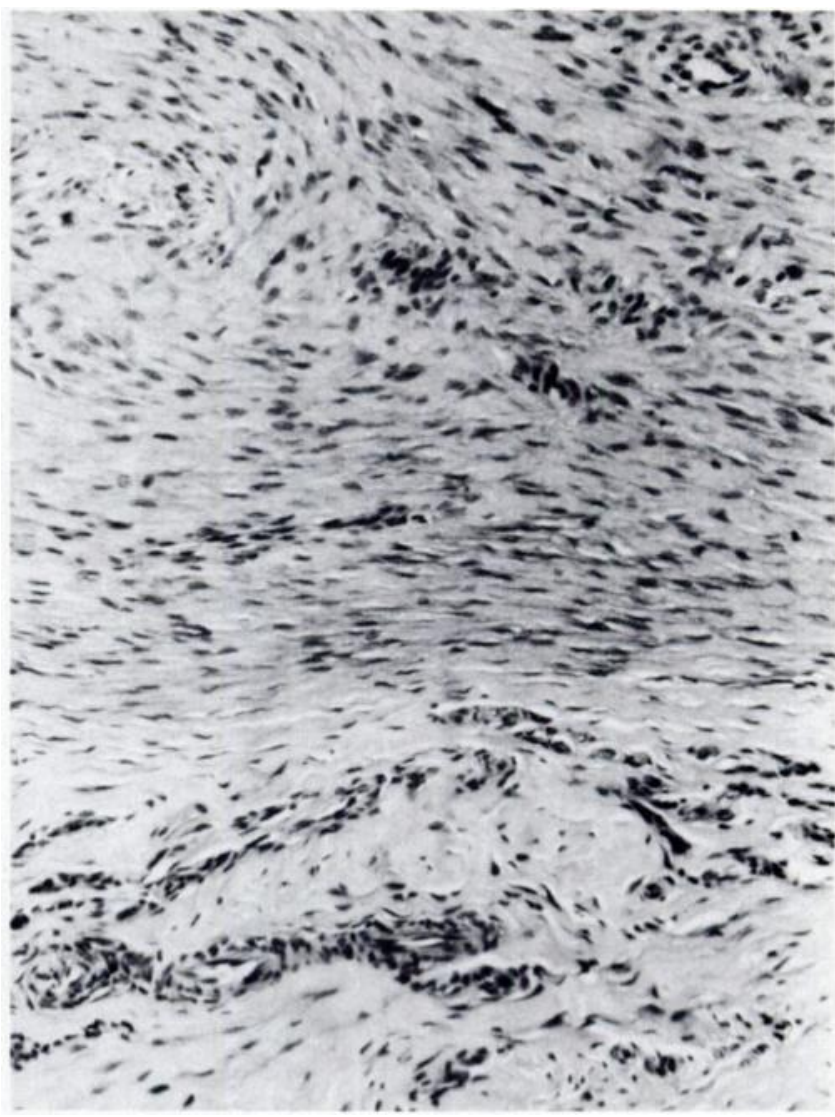

Fig. 5

Histological section showing typical Dupuytren's tissue (haemotoxylin and eosin, $\times 180$ ).

In January 1982 the knuckle pads were explored through dorsal curvilinear incisions. The skin was densely adherent to the underlying central slip of the extensor mechanism. Dissection was difficult. The lateral slips

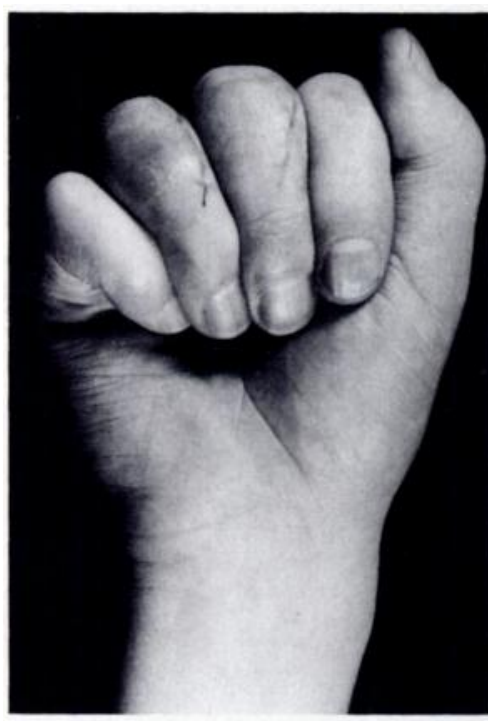

Fig. 6

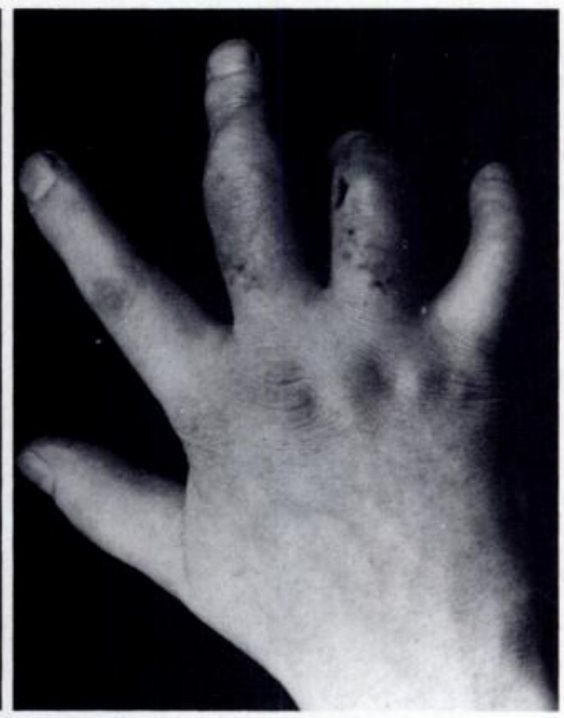

Fig. 7

After operation. Figure 6-Improved range of flexion. Figure 7-Extension. 
were stuck to the central slip by Dupuytren's tissue and were unable to glide laterally. By freeing the central slip from the lateral slips increased passive flexion at the proximal interphalangeal joint was possible, but a posterior capsulotomy was necessary before full flexion was obtained. Biopsies of the material infiltrating the skin and extensor mechanisms were taken. Histological examination showed typical Dupuytren's tissue (Fig. 5).

After 48 hours the patient was encouraged with physiotherapy to mobilise his fingers. The range of movements two weeks after exploration of the knuckle pads was significantly improved. Almost full flexion was possible (Figs 6 and 7).

\section{DISCUSSION}

Whilst knuckle pads are seen in association with a relatively high proportion of Dupuytren's contractures, it must be extremely rare for them to cause significant problems. In this relatively young man with severe disease, however, the knuckle-pad tissue caused tethering of the skin and the lateral extensor slips to the central slip, resulting in a swan-neck type of deformity and inability to flex the proximal interphalangeal joint. Extensor tendon involvement to such a degree with knuckle pads has not previously been described, nor the dramatic improvement in movement following operation.

It gives pleasure to acknowledge the help and encouragement of Mr Donal Brooks, whose case this was. I am also indebted to Ms U. Bundy of the Photographic Department of the Royal National Orthopaedic Hospital, London, and to Mrs Stevinson for typing the manuscript.

\section{REFERENCES}

Garrod AE. On an unusual form of nodule upon the joints of the fingers. St Bart's Hosp Rep 1893;29:157.

Hueston JT. Dupuytren's contracture. Edinburgh: Livingstone, 1963:51.

Mikkelsen OA. Knuckle pads in Dupuytren's disease. Hand 1977;9:301-5.

Wilson WF. Shearer's knuckles. Aust NZ J Surg 1972;42:192-3. 